Review

\title{
Identifying the Best Anticancer Agent Combination in TACE for HCC Patients: A Network Meta-analysis
}

\author{
Tao Guo*, Ping $\mathrm{Wu}^{*}$, Pengpeng Liu*, Baiyang Chen, Xiang Jiang, Yang Gu, Zhisu Liu ${ }^{\bowtie}$, Zhen $\mathrm{Li}^{\bowtie}$ \\ Department of General Surgery, Zhongnan Hospital of Wuhan University, Wuhan 430071, P.R. China \\ "These authors contributed equally to this work \\ $\triangle$ Corresponding authors: Zhen Li (Doctor1989@whu.edu.cn) and Zhisu Liu (2713845151@qq.com), Department of General Surgery, Zhongnan Hospital of \\ Wuhan University, Donghu Road 169, Wuhan 430071, China. Tel.: +86 027-67812588 \\ (C) Ivyspring International Publisher. This is an open access article distributed under the terms of the Creative Commons Attribution (CC BY-NC) license \\ (https://creativecommons.org/licenses/by-nc/4.0/). See http://ivyspring.com/terms for full terms and conditions.
}

Received: 2018.01.20; Accepted: 2018.04.14; Published: 2018.06.23

\begin{abstract}
Objective: We conducted a network meta-analysis to comprehensively compare various anticancer agents used in transarterial chemoembolization (TACE) based on the Bayesian theorem.

Methods: Globally recognized electronic databases, including PubMed, EMBASE, and Cochrane Central, were searched to retrieve relevant randomized controlled trials (RCTs) comparing anticancer agents in TACE for hepatocellular carcinoma $(\mathrm{HCC})$ patients. The therapeutic response, adverse events and overall survival rate were selected as parametric data to evaluate the clinical efficacy. Quantitative network meta-analysis and pair-wise analysis were conducted to compare the relative parameters.

Results: Of the 4242 retrieved articles, 17 RCTs containing 2330 patients fulfilled the inclusion criteria. The network meta-analysis exhibited that the application of anthracycline and mitomycin plus pyrimidine presented the best clinical values regarding all parametric data (probability $P=0.45$, 0.32 and 0.35 regarding comparison of response rate, adverse event and overall survival, respectively). Accordingly, further investigation on specific anticancer agents indicated that the combination of doxorubicin and mitomycin plus gemcitabine was the best agent combination in TACE (probability $P=0.49,0.37$ and 0.77 regarding comparison of response rate, adverse event and overall survival, respectively). Moreover, an additional study indicated that the single use of an anticancer agent prior to embolism brought no benefit compared with bland embolism without any agent (Test $Z=0.15,0.84,1.22$ and $P=0.88,0.40,0.22$ regarding comparison of response rate, adverse event and overall survival, respectively). However, the combined use of anticancer agents in TACE showed significantly better clinical efficacy than single use (Test $Z=4.40,3.94,0.24$ and $P<0.001,<0.001,=0.81$ regarding comparison of response rate, adverse event and overall survival, respectively); thus, combination utilization was recommended.

Conclusions: The combined use of anticancer agents in TACE was recommended. Application of anthracycline and mitomycin plus pyrimidine seemed to be the best choice for clinical consideration. Additionally, the combination of doxorubicin and mitomycin plus gemcitabine may be the best specific anticancer agent combination in TACE currently, although additional RCTs are expected to support our conclusion.
\end{abstract}

Key words: Anticancer agent; TACE; Network meta-analysis.

\section{Introduction}

Hepatocellular carcinoma (HCC) is one of the most common malignancies worldwide and the third leading cause of cancer-related death globally [1-2].
Although HCC management continues to develop [34], its therapeutic effect and molecular mechanism exploration remain unsatisfactory. Overall, the 
prognosis is extremely poor with the incidence closely matching mortality. Potentially curative options, including transplantation, resection or ablation, are applicable in less than $30 \%$ of patients who meet defined criteria. Therefore, most patients are treated with palliative intent. For unresectable HCC or preoperative treatment, transarterial chemoembolization (TACE) is an established local therapy in patients with advanced cirrhosis, and it confers significant survival benefits [5-6]. It is the current standard of care for patients with large or multinodular HCC, preserved liver function, absence of cancer-related symptoms, and no evidence of vascular invasion or extrahepatic spread [7- 8]. However, agreement regarding the best TACE technique has not yet been reached, and various options concerning the delivery systems, anticancer and embolic agents injected, and repetition schedules are still in use, making the results reported in the literature very inhomogeneous [9]. Technically, TACE comprises the intra-arterial injection of a chemotherapeutic drug followed by embolization of the blood vessel, resulting in a strong cytotoxic effect enhanced by ischemia. Thus, under the hypoxic microenvironment that is established by the embolization of tumor nutritious vessels, the therapeutic effects may depend on the anticancer agents.

By far, more attention has been given to improving the technology and form of TACE. For instance, drug-loaded microspheres have been introduced as a novel device capable of ensuring more sustained and tumor-selective drug delivery and permanent embolization [10]. Additionally, 2 meta-analyses have demonstrated that this device was superior to conventional TACE [11- 12]. However, they also declared their conclusions were not sufficiently reliable, and confirming its superiority needs more objective supporting evidence. On the other hand, we know that the anticancer agents used in TACE may bring significant clinical efficacy. However, it is a very heterogeneous option to select a specific drug application [13]. Nevertheless, many randomized controlled trials (RCTs) comparing different anticancer drugs used in TACE have been published. Surprisingly, few relative quantitative reviews and analyses have been reported. Given these abovementioned facts, in this research, we aimed to conduct a comprehensive quantitative review to compare various anticancer agents based on a network meta-analysis. Additionally. we plan to identify the best anticancer agent combination in TACE and further explore the role of these agents in this field.

\section{Methods}

In the current study, we chose therapeutic response, adverse events and overall survival rate as parametric data to estimate the clinical effectiveness of various anticancer drugs. Quantitative network meta-analysis and direct pair-wise comparisons were conducted.

\section{Data Sources and Search Strategy}

This review was conducted using a predefined protocol and was performed in accordance with PRISMA guidelines [14]. To avoid local publication bias, the study must have originated from studies that could be found in globally recognized databases. Electronic online retrieval was performed using Pubmed, EMBASE, and Cochrane Library (CENTRAL). The search strings were based on MeSH terms, including "TACE", "transarterial chemoembolization", "transcatheter arterial chemoembolization", "randomized controlled trial", "random" and "prospective". Different combinations of these terms were used for the searches. The studies were not limited to specific languages, although an Englishlanguage abstract had to be available for each study. We also referred to the full text when necessary to clarify the eligibility status.

\section{Study Selection and Eligibility Criteria}

Inclusion criteria were as follows: 1) RCTs (randomized controlled trials) that investigated different anticancer agents (including bland embolism) in TACE for HCC patients; 2) English-language titles or abstracts must be located in abovementioned databases; and 3) each study must provide at least 1 piece of relative parametric data.

The exclusion criteria were as follows: 1) Cohort retrospective, non-randomized cross-sectional, and other observational studies; 2 ) incomplete raw data; 3 ) experiments on cells or animals; 4) reviews, study protocols, comments, or case reports; and 5) full text could not be traced.

\section{Data Extraction and Outcomes of Interest}

We reviewed the full manuscripts of eligible studies and entered the extracted information, including the publication data (first author's name, year of publication, and country of the population under examination), interventions, and specific agents, into a pre-designed electronic file. To compare the clinical efficacy of various anticancer agents, we selected 3 parameters - the therapeutic response rate, adverse events and overall survival rate-to evaluate the curative value, safety and long-term outcome. These parametric data would be extracted for quantitative analysis. 


\section{Evaluation of Recommendation for Results}

To confirm the reliability and quality of current study, the Grades of Recommendations Assessment, Development and Evaluation (GRADE) system was selected to assess the methodological quality of evidence [15]. Five factors that may reduce the quality of evidence were considered (research limitations, inconsistent findings, uncertain direct evidence, inaccuracy or wide confidence interval, and publication bias). Additionally, three factors that can enhance the quality of evidence were also reviewed (effect size, possible confounding factors, and dose-effect relationship). Each direct comparison between 2 different drugs were considered in detailed and were rated based on these factors. A comprehensive description of the evidence quality for each parametric data was presented.

\section{Statistical Analysis}

For the current research, we focused on the clinical efficacy of different anticancer interventions in TACE. Thus, it was necessary to make comprehensive network comparisons based on the Bayesian theorem to determine the best anticancer drug or/and specific agent in TACE for HCC patients. This approach can be considered an extension of the traditional pair-wise meta-analysis because it incorporates both direct and indirect information through a common comparator to obtain estimates of the relative interventional effects on multiple intervention comparisons [16-17]. For network quantitative analysis, we evaluated the consistency by combining the quantitative estimates from the indirect comparisons according to the experimental design and primary outcome of the included studies. Meanwhile, node-splitting analysis was also performed and showed no statistical inconsistency at $\mathrm{P}>0.05$. If there was no relevant inconsistency in the evidence, a consistency model was used to draw conclusions about the relative effect of the included interventions. Probability $P$ values were calculated for the best therapeutic intervention. Additionally, the relevant rank of $P$ values were presented to clarify the pros and cons of different anticancer agents. Convergence was assessed to calculate the Potential Scale Reduction Factor (PSRF), and values were limited to 1 to complete the calculation. For subgroup analysis, if whole network connections could not be established, superior interventions were presented for the comprehensive description.

Moreover, for some certain interventions, pair-wise analysis was conducted to complete direct comparisons for further investigation. In this situation, heterogeneity ( $\mathrm{I}^{2}$ index statistic) in the study design was used to estimate a data mode for using fixed- $\left(\mathrm{I}^{2}<50 \%\right)$ or random- $\left(\mathrm{I}^{2}>50 \%\right)$ effects models [18]. The associated 95\% confidence intervals (CIs) were calculated, and $\mathrm{P}<0.05$ was considered to indicate statistical significance. The automated software Aggregate Data Drug Information System (ADDIS, version 1.16) was used for the network-pooled estimation. Explanations for Cochrane Summary of Findings Table of GRADE system were determined using GRADEprofiler software (version 3.6). Data manipulation and statistical analyses of pair-wise analysis were conducted using the Stata software package (version 12.0).

\section{Results}

\section{Study Selection and Characteristics}

After removal of duplicates, we retrieved 4242 records from the literature search (Figure 1). The titles and abstracts of these records were reviewed, and 17 studies containing $2330 \mathrm{HCC}$ patients were finally selected for full-text review [19-35]. Among them, the therapeutic response rate [19-21, 23- 28, 30-35] and adverse events [19-25, 27-33,35] were reported in 15 studies. Additionally, 14 papers provided the parametric data of the overall survival rate [19-23, 25, 27- 29, 31-35]. On the other hand, to evaluate the efficacy from different aspects, we classified the included anticancer drugs as simplified intervention and specific agents (Supplementary Table S1). Fifteen studies [19- 20, 22- 28, 30-35] reported the use of various anticancer interventional drugs, including anthracycline, platinum, mitomycin (mitomycin C), pyrimidine, raltitrexed, ethanol and their combinations. Additionally, 12 specific agents from all 17 studies and their combinations from these studies were presented (Supplementary Table S1) (Table 1).

\section{Therapeutic Response Rate}

In the current study, the therapeutic response was defined as the objective therapy response (complete response plus partial response), which was used to evaluate the efficiency of treatment. All the relative data were extracted and pooled before analysis. First, we pooled the results from 14 studies containing 10 therapeutic interventions (Figure 2A). After quantitative analysis, we found that the combination of anthracycline and mitomycin plus pyrimidine exhibited the best therapeutic response rate (probability $P=0.45$ ), followed by ethanol (probability $P=0.31$ ) (Table 2) (Supplementary Table S2). Next, we further investigated the objective therapy response of various specific agents from 15 included studies (Figure 2B). The results showed that the combination of doxorubicin and mitomycin plus 
gemcitabine revealed the best therapeutic response (probability $P=0.49$ ) (Table 2), followed by the application of ethanol (probability $P=0.34$ ) (Table 2) (Supplementary Table S2).

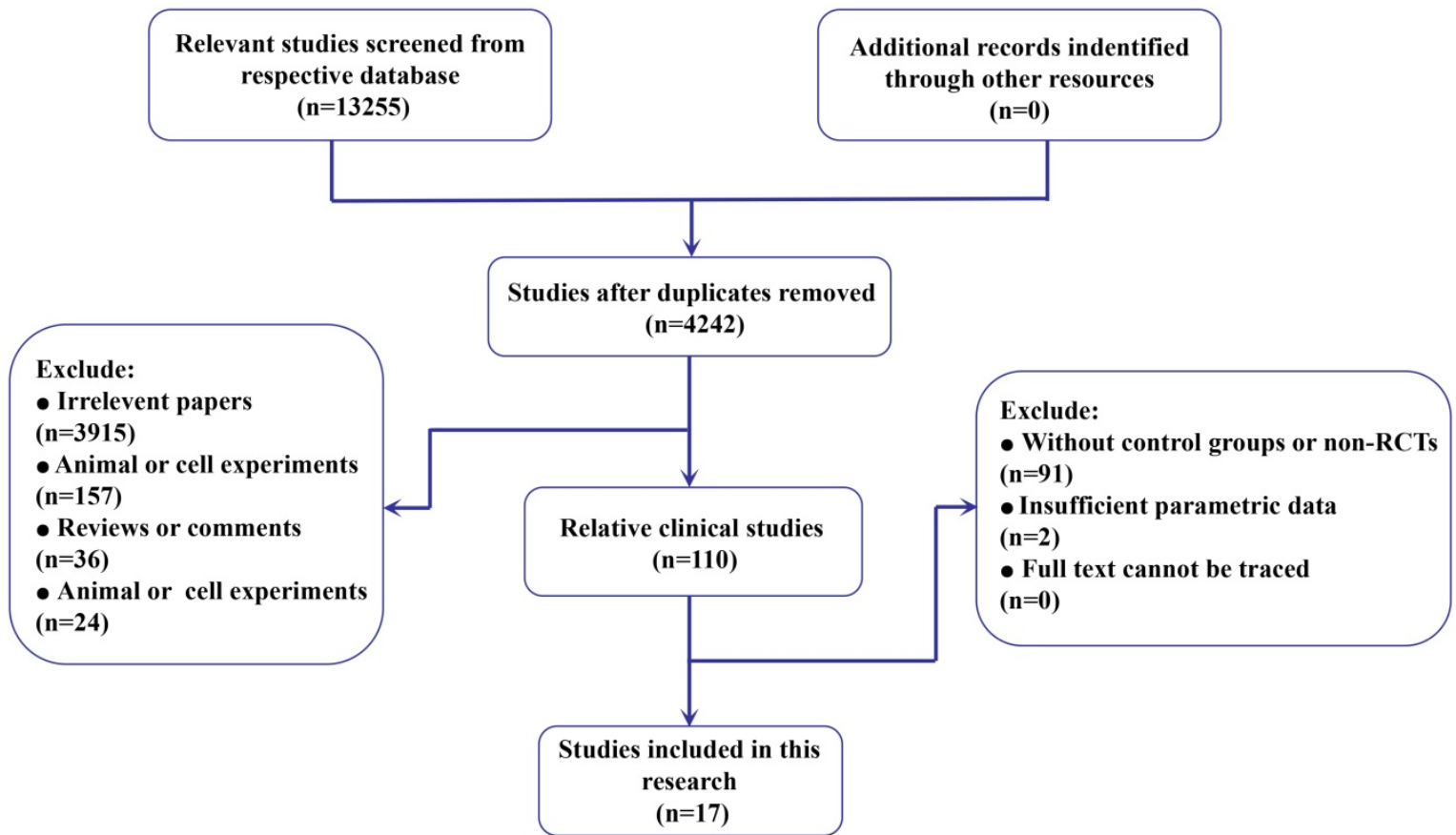

Figure 1. Flow diagram of the process of (and the reasons for) including and excluding studies for this meta-analysis.

Table 1. Characteristics of the included trials

\begin{tabular}{|c|c|c|c|c|c|c|c|}
\hline Author & $\begin{array}{l}\text { Time of } \\
\text { Pub. }\end{array}$ & Country & $\begin{array}{l}\text { Study } \\
\text { Arms }\end{array}$ & Interventions & Detaied drugs & $\begin{array}{l}\text { Sample } \\
\text { Size }\end{array}$ & Available Parameter \\
\hline $\begin{array}{l}\text { Brown } \\
{[19]}\end{array}$ & 2016 & USA & 2 & Anthracycline vs. Bland & Doxorubicin vs. Bland & $50 / 51$ & $\begin{array}{l}\text { Response Rate; Adverse } \\
\text { Events; Survival Rate }\end{array}$ \\
\hline $\begin{array}{l}\text { Chang } \\
{[20]}\end{array}$ & 1994 & China & 2 & Platinum vs. Bland & Cisplatin vs. Bland & $22 / 24$ & $\begin{array}{l}\text { Response Rate; Adverse } \\
\text { Events; Survival Rate }\end{array}$ \\
\hline $\begin{array}{l}\text { Golfieri } \\
{[21]}\end{array}$ & 2014 & Italy & 2 & - & Doxorubicin vs. Epirubicin & $89 / 88$ & $\begin{array}{l}\text { Response Rate; Adverse } \\
\text { Events; Survival Rate }\end{array}$ \\
\hline Ikeda [22] & 2017 & Japan & 2 & Platinum vs. Anthracycline & Miriplatin vs. Epirubicin & $124 / 123$ & $\begin{array}{l}\text { Adverse Events; Surviva } \\
\text { Rate }\end{array}$ \\
\hline Kawai [23] & 1992 & Japan & 2 & Anthracycline vs. Bland & Adriamycin vs. Bland & $145 / 137$ & $\begin{array}{l}\text { Response Rate; Adverse } \\
\text { Events; Survival Rate }\end{array}$ \\
\hline $\begin{array}{l}\text { Kubota } \\
{[24]}\end{array}$ & 2017 & Japan & 2 & Platinum vs. Anthracycline & Miriplatin vs. Epirubicin & $99 / 99$ & $\begin{array}{l}\text { Response Rate; Adverse } \\
\text { Events }\end{array}$ \\
\hline Liu [25] & 2014 & China & 3 & $\begin{array}{l}\text { Anthracycline vs. Anthracycline + Mitomycin } \\
\text { vs. Anthracycline + Mitomycin + Pyrimidine }\end{array}$ & $\begin{array}{l}\text { Doxorubicin vs. Doxorubicin + Mitomycin } \\
\text { vs. Doxorubicin + Mitomycin + Gemcitabine }\end{array}$ & $50 / 59 / 53$ & $\begin{array}{l}\text { Response Rate; Adverse } \\
\text { Events; Survival Rate }\end{array}$ \\
\hline Llovet [26] & 2002 & Spain & 2 & Anthracycline vs. Bland & Doxorubicin vs. Bland & $40 / 37$ & Response Rate; \\
\hline $\begin{array}{l}\text { Malagari } \\
{[27]}\end{array}$ & 2010 & Greece & 2 & Anthracycline vs. Bland & Doxorubicin vs. Bland & $41 / 43$ & $\begin{array}{l}\text { Response Rate; Adverse } \\
\text { Events; Survival Rate }\end{array}$ \\
\hline Meyer [28] & 2013 & UK & 2 & Platinum vs. Bland & Cisplatin vs. Bland & $43 / 38$ & $\begin{array}{l}\text { Response Rate; Adverse } \\
\text { Events; Survival Rate }\end{array}$ \\
\hline Otsuji [29] & 2015 & Japan & 2 & - & Miriplatin vs. Cisplatin & $49 / 49$ & $\begin{array}{l}\text { Adverse Events; Surviva } \\
\text { Rate }\end{array}$ \\
\hline $\begin{array}{l}\text { Sahara } \\
{[30]}\end{array}$ & 2010 & Japan & 2 & Platinum vs. Anthracycline & Cisplatin vs. Epirubicin & $12 / 16$ & $\begin{array}{l}\text { Response Rate; Adverse } \\
\text { Events }\end{array}$ \\
\hline $\begin{array}{l}\text { Sahara } \\
{[31]}\end{array}$ & 2012 & Japan & 2 & $\begin{array}{l}\text { Platinum + Anthracycline + Mitomycin + } \\
\text { Pyrimidine vs. Anthracycline }\end{array}$ & $\begin{array}{l}\text { Epirubicin + Cisplatin + Mitomycin + } \\
\text { Furuorouracil vs. Epirubicin }\end{array}$ & $24 / 27$ & $\begin{array}{l}\text { Response Rate; Adverse } \\
\text { Events; Survival Rate }\end{array}$ \\
\hline Shi [32] & 2012 & China & 2 & $\begin{array}{l}\text { Platinum + Anthracycline + Mitomycin vs. } \\
\text { Anthracycline }\end{array}$ & $\begin{array}{l}\text { Epirubicin + Lobaplatin + Mitomycin vs. } \\
\text { Epirubicin }\end{array}$ & $122 / 122$ & $\begin{array}{l}\text { Response Rate; Adverse } \\
\text { Events; Survival Rate }\end{array}$ \\
\hline $\begin{array}{l}\text { Somma } \\
{[33]}\end{array}$ & 2015 & Italy & 2 & Ethanol vs. Anthracycline & Ethanol vs. Epirubicin & $45 / 42$ & $\begin{array}{l}\text { Response Rate; Adverse } \\
\text { Events; Survival Rate }\end{array}$ \\
\hline Wang [34] & 2014 & China & 2 & Platinum vs. Anthracycline & Lobaplatin vs. Pirarubicin & $90 / 83$ & $\begin{array}{l}\text { Response Rate; Survival } \\
\text { Rate }\end{array}$ \\
\hline Zhao [35] & 2016 & China & 3 & Raltitrexed vs. Pyrimidine vs. Anthracycline & Raltitrexed vs. Fluorouracil vs. Doxorubicin & $76 / 76 / 75$ & $\begin{array}{l}\text { Response Rate; Adverse } \\
\text { Events; Survival Rate }\end{array}$ \\
\hline
\end{tabular}



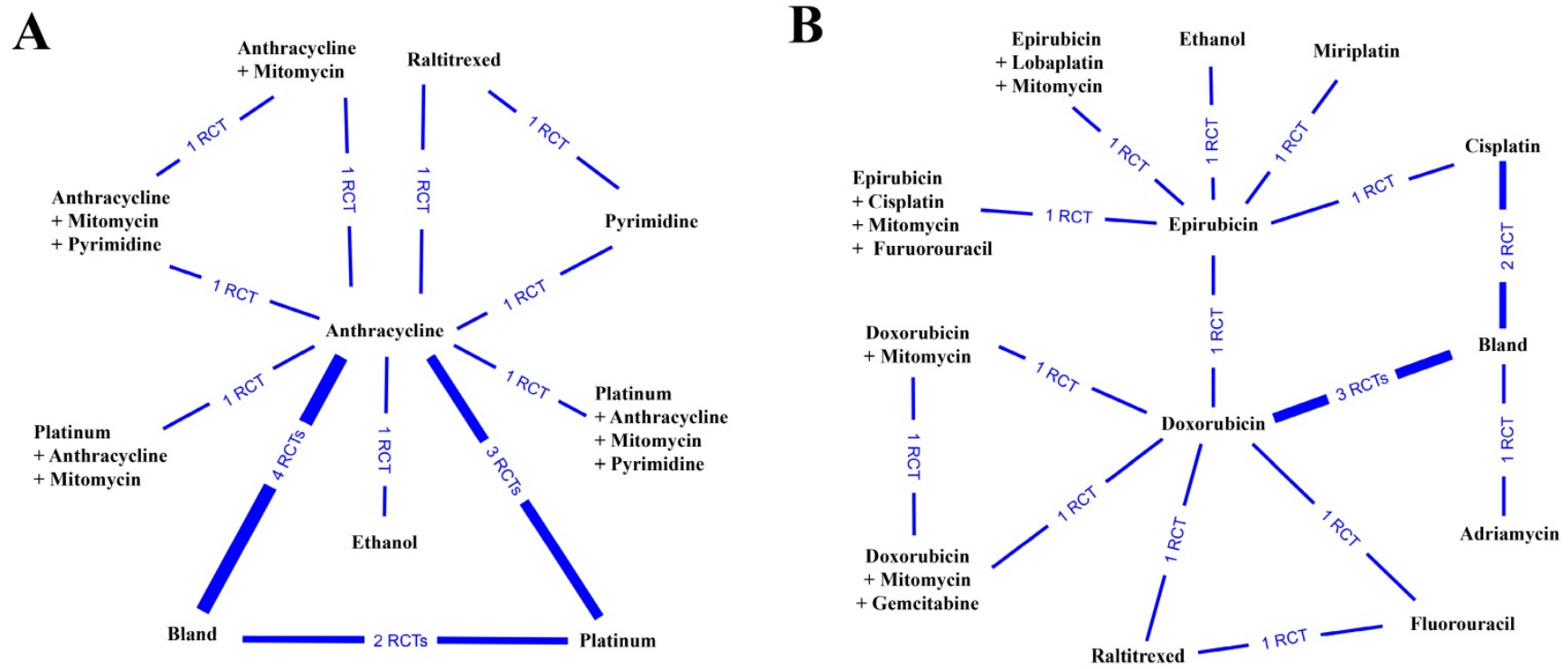

Figure 2. Network connections of the included studies to compare the therapeutic response rate for (A) anticancer medical interventions and (B) specific anticancer agents.

Table 2. Results of cumulative probability $P$ values regarding different parametric data.

\begin{tabular}{|c|c|c|c|c|c|c|}
\hline \multirow[t]{2}{*}{ Ranks } & \multicolumn{2}{|l|}{ Response rate } & \multicolumn{2}{|l|}{ Adverse event } & \multicolumn{2}{|l|}{ Overall survival } \\
\hline & Interventions $(P)$ & Specific agents $(P)$ & Interventions $(P)$ & Specific agents $(P)$ & Interventions $(P)$ & Specific agents $(P)$ \\
\hline Rank 1 & $\begin{array}{l}\text { Anthracycline }+ \\
\text { Mitomycin + Pyrimidine } \\
(P=0.45)\end{array}$ & $\begin{array}{l}\text { Doxorubicin + } \\
\text { Mitomycin + } \\
\text { Gemcitabine } \\
(P=0.49)\end{array}$ & $\begin{array}{l}\text { Anthracycline }+ \\
\text { Mitomycin + Pyrimidine } \\
(P=0.32)\end{array}$ & $\begin{array}{l}\text { Doxorubicin + } \\
\text { Mitomycin + } \\
\text { Gemcitabine } \\
(P=0.37)\end{array}$ & $\begin{array}{l}\text { Anthracycline }+ \\
\text { Mitomycin + Pyrimidine } \\
(P=0.35)\end{array}$ & $\begin{array}{l}\text { Doxorubicin + } \\
\text { Mitomycin + } \\
\text { Gemcitabine } \\
(P=0.77)\end{array}$ \\
\hline Rank 2 & $\begin{array}{l}\text { Ethanol } \\
(P=0.31)\end{array}$ & $\begin{array}{l}\text { Ethanol } \\
(P=0.34)\end{array}$ & $\begin{array}{l}\text { Ethanol } \\
(P=0.22)\end{array}$ & $\begin{array}{l}\text { Ethanol } \\
(P=0.25)\end{array}$ & $\begin{array}{l}\text { Platinum }+ \\
\text { Anthracycline + } \\
\text { Mitomycin } \\
(P=0.28)\end{array}$ & $\begin{array}{l}\text { Epirubicin + Lobaplatin } \\
+ \text { Mitomycin } \\
(P=0.07)\end{array}$ \\
\hline Rank 3 & $\begin{array}{l}\text { Platinum + } \\
\text { Anthracycline + } \\
\text { Mitomycin } \\
(P=0.22)\end{array}$ & $\begin{array}{l}\text { Epirubicin + Lobaplatin } \\
+ \text { Mitomycin } \\
(P=0.15)\end{array}$ & $\begin{array}{l}\text { Raltitrexed } \\
(P=0.21)\end{array}$ & $\begin{array}{l}\text { Raltitrexed } \\
(P=0.13)\end{array}$ & $\begin{array}{l}\text { Ethanol } \\
(P=0.20)\end{array}$ & $\begin{array}{l}\text { Ethanol } \\
(\mathrm{P}=0.07)\end{array}$ \\
\hline Rank 4 & $\begin{array}{l}\text { Anthracycline }+ \\
\text { Mitomycin }(P=0.02)\end{array}$ & $\begin{array}{l}\text { Doxorubicin }+ \\
\text { Mitomycin } \\
(\mathrm{P}=0.02)\end{array}$ & $\begin{array}{l}\text { Pyrimidine } \\
(P=0.20)\end{array}$ & $\begin{array}{l}\text { Pyrimidine } \\
(P=0.10)\end{array}$ & $\begin{array}{l}\text { Raltitrexed } \\
(P=0.15)\end{array}$ & $\begin{array}{l}\text { Raltitrexed } \\
(P=0.03)\end{array}$ \\
\hline Rank 5 & - & - & $\begin{array}{l}\text { Platinum }+ \\
\text { Anthracycline }+ \\
\text { Mitomycin + Pyrimidine } \\
(P=0.02)\end{array}$ & $\begin{array}{l}\text { Fluorouracil } \\
(P=0.03)\end{array}$ & $\begin{array}{l}\text { Anthracycline + } \\
\text { Mitomycin } \\
(P=0.01)\end{array}$ & $\begin{array}{l}\text { Epirubicin + Cisplatin }+ \\
\text { Mitomycin }+ \\
\text { Furuorouracil } \\
(P=0.03)\end{array}$ \\
\hline
\end{tabular}

\section{Safety Evaluation}

To estimate the safety of the anticancer interventions, we analyzed the parametric data of adverse events. After pooling and calculating the relative data from 13 studies containing 10 anticancer interventions (Figure 3A), we demonstrated that the combination of anthracycline and mitomycin plus pyrimidine was the safest anticancer intervention in TACE (probability $P=0.32$ ), followed by ethanol (probability $P=0.22$ ) (Table 2) (Supplementary Table S3). Furthermore, 15 studies reported adverse events after utilizing 13 specific agents and/or their combinations (Figure 3B). The results illustrated that the combination of doxorubicin and mitomycin plus gemcitabine was the safest anticancer agent for utilization in TACE (probability $P=0.37$ ). Similarly, ethanol ranked in second place (probability $P=0.25$ ) (Table 2) (Supplementary Table S3).

\section{Assessment of the Overall Survival Rate}

Due to the limitations of insufficient data, we only compared the 1- and 2-year overall survival rates based on a network meta-analysis to assess the long-term outcome. Additionally, all relative data were pooled and estimated together. Twelve included papers provided 1- and 2-year survival rates after TACE with various anticancer interventions (Figure $4 \mathrm{~A})$. The objective results demonstrated that the application of anthracycline and mitomycin plus pyrimidine was the best approach to enhance the overall survival rate (probability $P=0.35$ ) (Table 2) (Supplementary Table S4). In addition, we analyzed the data of the overall survival rate from 14 studies comparing different specific anticancer agents (Figure 4B). After quantitative network meta-analysis, we found that the combination of doxorubicin and mitomycin plus gemcitabine seemed to be the best 

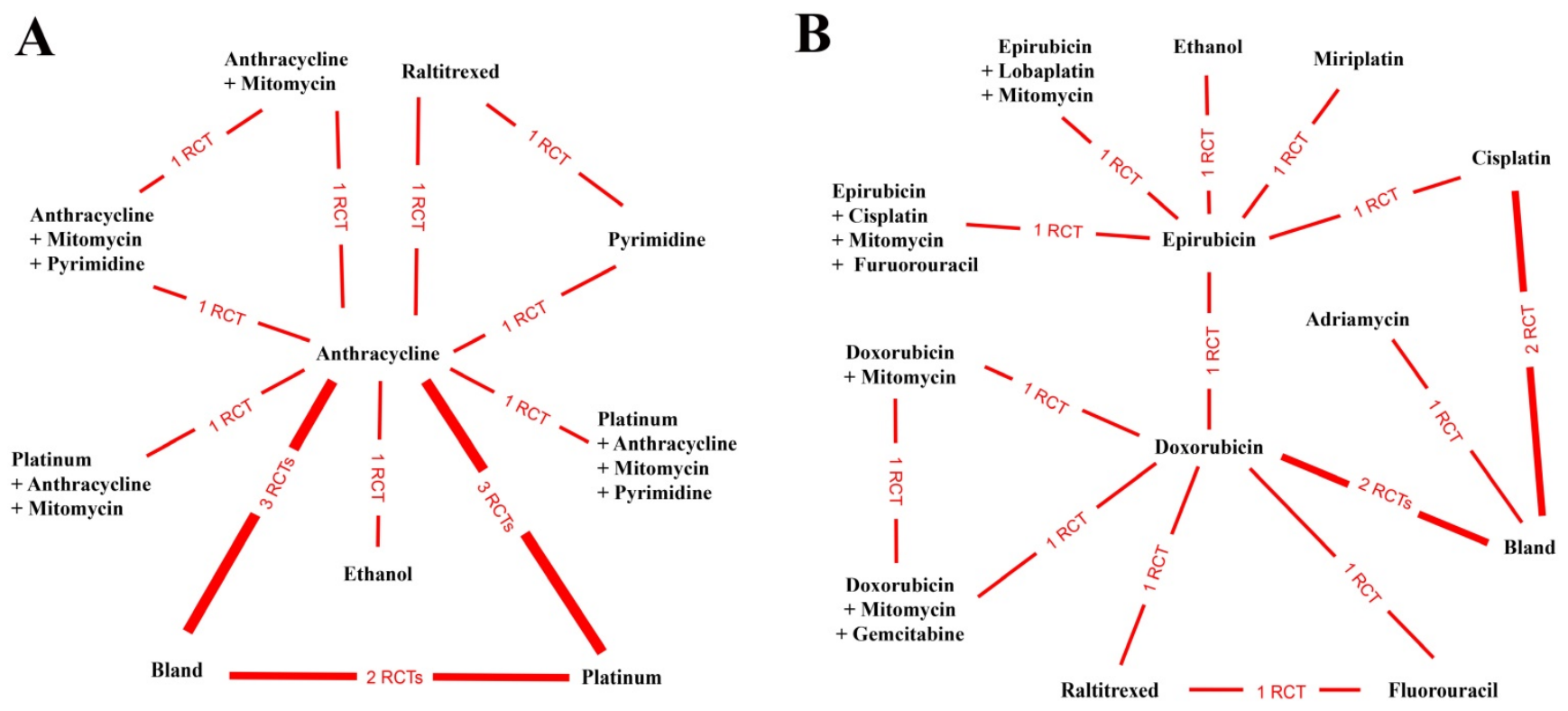

Figure 3. Network connections of included studies for the comparisons of adverse events for (A) anticancer medical interventions and (B) specific anticancer agents.
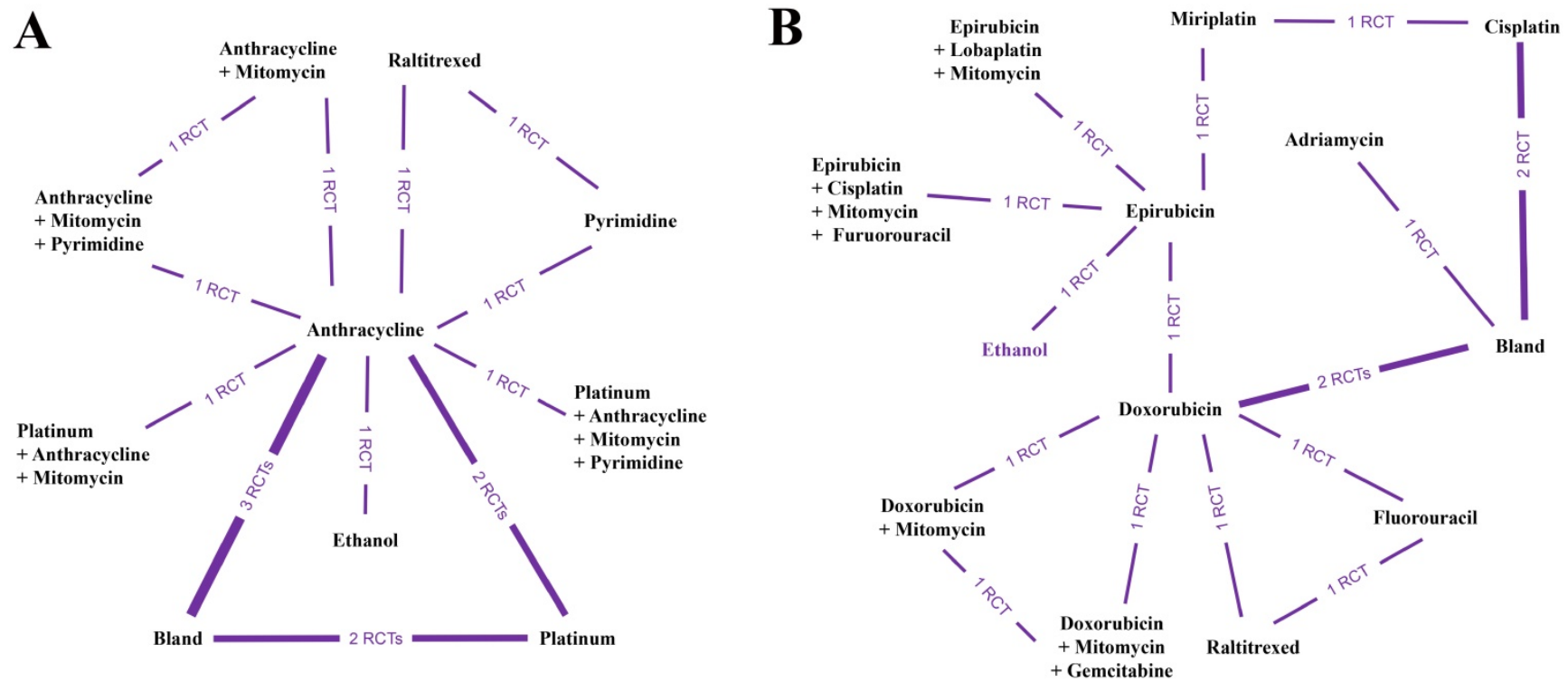

Figure 4. Network connections of included studies for comparisons of the overall survival rate for (A) anticancer medical interventions and (B) specific anticancer agents.

agent combination to improve the overall survival rate (probability $P=0.77$ ) (Table 2) (Supplementary Table S4).

\section{Node-splitting Analysis and Evidence Recommendation}

Thus far, we have analyzed 3 parametric datasets to evaluate the clinical efficacy of different anticancer interventions applied in TACE based on quantitative network comparisons in a consistency model. Here, we aimed to determine whether there was any relevant inconsistency in the objective evidence. Thus, we carried out node-splitting analysis, and the results demonstrated that no inconsistency existed in our results regarding the parametric data of the therapeutic response (Supplementary Table S5), adverse events (Supplementary Table S6) and overall survival rate (Supplementary Table S7).

Additionally, by focusing on the therapeutic response, adverse events and overall survival rate, based on the relationships between each intervention (and/or specific agent) and GRADE system, we evaluated the quality of the evidence via respective direct comparisons. The results exhibited that the quality of our objective data analysis was ranked as high or moderate for analysis of the therapeutic response (Supplementary Table S8), adverse events (Supplementary Table S9) and overall survival rate (Supplementary Table S10). Additionally, no 
low-quality or very low-quality evidence existed. Based on all these facts, we deduced that our results were reliable and recommendable.

\section{Subgroup Analysis}

Regarding the therapeutic response, evaluation criteria continue to develop, and our included papers may contain different standards for the estimation of the objective response according to the European Association for the Study of the Liver (EASL) [36], RECIST [37] and modified RECIST (mRECIST) [3839]. The mRECIST standard was the latest updated standard to assess the tumor response of treatment. Thus, we conducted subgroup analysis by comparing the objective response according to mRECIST. Pooled estimation of 8 interventions from 6 studies (Supplementary Figure S1A) revealed that the application of anthracycline and mitomycin plus pyrimidine in TACE was the most effective approach to enhance the therapeutic response rate (probability $P=0.64$ ). Based on these 8 interventions, we further investigated 10 specific agents used in TACE and compared their therapeutic response according to the mRECIST standard (Supplementary Figure S1B). The results revealed that the best agent combination to improve the therapeutic response was the combination of doxorubicin and mitomycin plus gemcitabine (probability $P=0.73$ ).

The Common Terminology Criteria for Adverse Events (CTCAE) system is commonly used to estimate the adverse effects after TACE for HCC patients [40]. In the current study, we found that different CTCAE versions (2.0, 3.0 and 4.0) were used in the respective included studies. Therefore, we conducted subgroup analysis to figure out the safest intervention and/or specific agent by comparing the parametric data of the adverse events measured by CTCAE 4.0, which is the latest version. After pooling of the relative data, we performed subgroup network meta-analysis based on 6 interventions from 4 studies (Supplementary Figure S2A). Coinciding with the previous analysis, the results showed that the application of anthracycline and mitomycin plus pyrimidine was the safest approach in TACE (probability $P=0.61$ ). We next tried to compare the adverse events regarding specific agents measured by CTCAE 4.0 based on network meta-analysis. However, the whole net connection could not be established. Therefore, we compared the relative data separately according to the net connections (Supplementary Figure S2B). Regarding the results, we found that ethanol (probability $P=0.81$ ) and the combination of doxorubicin and mitomycin plus gemcitabine (probability $P=0.85$ ) seemed to be superior to other agents. However, the best agent combination was not addressed.
To further understand the role of the respective intervention and/or specific agent on the long-term outcome, we also conducted subgroup analysis of the overall survival rate regarding the follow-up time $(1$ year or 2 years). We first conducted subgroup analysis of the 1- and 2-year overall survival rates regarding different interventions (Supplementary Figure S3A). Unexpectedly, we found that the utilization of ethanol in TACE was the best approach to enhance the 1-year survival rate (probability $P=0.34$ ). Additionally, for a longer follow-up time, the combination of anthracycline and mitomycin plus pyrimidine presented the best efficacy to improve the 2-year survival time (probability $P=0.71$ ). Next, we analyzed the overall survival data similarly regarding the different specific agents (Supplementary Figure S3B). Again, ethanol (probability $P=0.58$ ) and doxorubicin plus mitomycin plus gemcitabine (probability $P=0.78$ ) were still the best agents for 1- and 2-year overall survival rate enhancement, respectively.

\section{Additional Investigation}

In our study, we included some papers comparing TACE with anticancer agents and bland embolism without agents. Thus, we performed further pair-wise meta-analysis to directly compare them and tried to find the exact role of anticancer agents in TACE. Six included studies that reported the single use of an anticancer agent versus bland embolism provided relative parametric data [19- 20, 23, 26- 28]. After quantitative analysis, we demonstrated no statistical significance between the single use of an anticancer agent and bland embolism regarding the therapeutic response rate (Test $Z=0.15$, $P=0.88$ ) (Supplementary Figure S4A), adverse events (Test $Z=0.84, P=0.40$ ) (Supplementary Figure S4B) and overall survival rate (Test $Z=1.22, \quad P=0.22$ ) (Supplementary Figure S4C). Our results illustrated that the single use of an anticancer agent in TACE may not reveal better clinical values.

Based on this, we suspected that the single use may limit the efficacy of anticancer agents. Additionally, according to the results, the combined use of anticancer drugs seemed to show superior probability $P$ values according to the parametric data (Table 2). Regarding the application of various anticancer drugs, we speculated that the combined utilization of anticancer drugs may lead to better outcomes than the single use. To confirm our hypothesis, we performed an additional investigation based on 3 included RCTs [25, 31- 32]. As expected, we directly compared the parametric data of the therapeutic response rate, adverse events and overall survival rate. We found that the combined use of anticancer drugs could bring a higher therapeutic 
response rate than the single use (Test $Z=4.04, P<$ 0.001) (Supplementary Figure S5A) and better enhancement of the overall survival rate (Test $Z=3.94$, $P<0.001$ ) (Supplementary Figure S5C). However, there was no significant difference between the combined use and single use regarding adverse events (Test $Z=0.24, P=0.81$ ) (Supplementary Figure $\mathrm{S5B}$ ). To some extent, this may indicate that combined use is better than single utilization.

\section{Discussion}

Although TACE is usually considered as a first-line treatment for intermediate unresectable HCC, it remains a heterogeneous procedure widely varying in terms of the drugs injected and embolic agents [41]. Furthermore, there is still disagreement on the best anticancer drugs to be administered. Simultaneously, there is a need for more effective drugs, with minimal toxicity to maintain the patients' quality of life because TACE is generally used as a palliative therapy option $[5,42]$. Thus, it is necessary to conduct a comprehensive quantitative analysis to provide evidence-based evaluation.

To our knowledge, this is the first quantitative analysis comparing various anticancer drugs in TACE. By analyzing 3 parametric datasets of the therapeutic response, adverse events and overall survival rate, we unexpectedly found that the application of an anthracycline combined with mitomycin plus pyrimidine revealed the best clinical value regarding all 3 parameters (probability $P=0.45$, 0.32 and 0.35 , respectively). Moreover, further investigation of 12 specific agents also demonstrated that the combination of doxorubicin and mitomycin plus gemcitabine may lead to the best clinical efficacy for all parameters tested (probability $P=0.49,0.37$ and 0.77, respectively) (Table 2). These consistently objective results fully addressed that an anthracycline combined with mitomycin plus pyrimidine is the best anticancer drug combination in TACE, and doxorubicin and mitomycin plus gemcitabine is considered the best agent combination currently. Doxorubicin may activate cytotoxic signaling, leading to DNA damage and mitochondrial dysfunction; thus, it is commonly used in TACE as an anticancer agent [43]. Additionally, mitomycin is often combined with an anthracycline (such as doxorubicin, epirubicin or pirarubicin) as a general option for utilization [44]. Gemcitabine was demonstrated to reveal activity in the inhibition of human hepatoma cells in vitro [4546], and it is also a pyrimidine antimetabolite that exhibits a broad range of activity against various tumors [47-48]. A previous retrospective study may argue that the application of gemcitabine may not be advantageous [49]. However, the validity of the study result was limited by the lack of randomization. Furthermore, recent new studies have indicated that gemcitabine was effective in TACE [50- 51]. In addition, further investigation by subgroup analysis (supplementary Figure S1- S3) according to the latest standards (mRECIST and CTCAE 4.0) also proved the superiority of the combination of doxorubicin and mitomycin plus gemcitabine. Thus, we considered the application of an anthracycline plus mitomycin with an additional pyrimidine as the best anticancer medication in TACE, and currently, the combination of doxorubicin and mitomycin plus gemcitabine seems to be the best specific agent combination.

In addition, after conducting an additional study, we determined that the use of a single anticancer agent in TACE revealed no benefit compared with using no agent (Supplementary Figure S4). This finding was consistent with that of a previous systematic review [52]. However, the combined use seemed to reveal a better therapeutic response rate (Supplementary Figure S5A) and to prolong the overall survival time (Supplementary Figure S5C). This indicated that the local therapy of chemoembolization may also depend on the accumulation of various anticancer agents; thus, the combined use of anticancer agents could enhance the clinical efficacy of TACE. Notably, combined use did not mean more agents will lead to a better response. For example, in the current study, an anthracycline combined with mitomycin plus pyrimidine revealed the best efficacy. However, when they were combined using a platinum agent, the effects seemed to be worse (Table 2). Moreover, an anthracycline combined with mitomycin and an additional platinum agent seemed to be worse than with an additional pyrimidine (Table 2). Based on these findings, we deduced that platinum agents may not be the most appropriate for combined use in TACE compared with pyrimidines. Therefore, a reasonable choice of agents is more important than increasing the number of agents. On the other hand, after considering the suitable combinations of anticancer agents, the application of ethanol also revealed great efficacy, and its effect should not be neglected. The results revealed that the effects of ethanol infusion seemed to be second only to the combination of anthracycline and mitomycin plus pyrimidine in different aspects (Table 2). Moreover, the application of ethanol led to the highest 1-year overall survival rate but showed no benefit for a longer survival outcome (Supplementary Figure S3). We understood that ethanol could be used for direct percutaneous injection for small HCC lesions. Unlike chemotherapeutic agents, ethanol could lead to protein coagulation in HCC cells and sequencing necrosis. Therefore, when it was used to substitute for 
an anticancer agent for TACE [53], it can exhibit strong local effects in the short term [54]. However, it does not seem to provide a good long-term survival benefit compared with the combined application of chemo agents (Supplementary Figure S3). Nevertheless, we propose and expect that it may be considered a good option in the TACE schedule, and it may have potential benefits when combined with chemical anticancer agents.

Among relative previous publications, many of them aimed to discuss the clinical value of TACE [55] or focused on the technical aspects [56- 57] with ignoring anticancer agents. Unlike the simple pair-wised comparison [52], our study aimed to further explore the superior anticancer agents used in TACE to perfect the TACE procedure based on a comprehensive quantitative network meta-analysis. Although we deemed the consistency of our data (Supplementary Table S5- 7) and level of evidence (Supplementary Table S8-10) to be reliable, there are still some shortcomings in this study. To ensure the authority of the analyzed data and avoid local bias, we applied stringent inclusion criteria to select appropriate studies and, therefore, might have overlooked some representative papers. Furthermore, most of the included RCTs were carried out in Asia, a situation that may cause some inevitable bias. Additionally, due to the individual differences in patients, some confounding factors may be presented in the original papers. In addition, although we had performed a comprehensive quantitative analysis containing 6 interventions and 12 specific anticancer agents, some of them were compared by only 1 RCT. This may make our results less robust. Additionally, we determined that the application of an anthracycline plus mitomycin with an additional pyrimidine was the best anticancer intervention. However, the relative data and comparison were provided from only 1 RCT [25]. Therefore, accordingly, the combination of doxorubicin and mitomycin plus gemcitabine was demonstrated to be the best agent so far. This conclusion could be unilateral and may be updated in the future. Thus, we expected that more well-designed RCTs could be reported.

Despite the existence of several limitations, our results illustrated that the application of an anthracycline and mitomycin plus a pyrimidine is the best anticancer intervention in TACE. Accordingly, we found that the combination of doxorubicin and mitomycin plus gemcitabine is the best specific anticancer agent so far. Moreover, we surmised that the single use of a chemotherapeutic agent may not cause any benefit compared with bland embolism without any anticancer agent. However, the combined utilization of anticancer agents in TACE could significantly enhance the relative clinical values. Notably, ethanol could be a novel substitute for a chemotherapeutic agent, and it may be a good option in the TACE schedule.

\section{Abbreviations}

TACE: transarterial chemoembolization; HCC: hepatocellular carcinoma; RCT: randomized controlled trial; GRADE: Grades of Recommendations Assessment, Development and Evaluation; PSRF: Potential Scale Reduction Factor; EASL: European Association for the Study of the Liver; RECIST: Response Evaluation Criteria in Solid Tumors; CTCAE: Common Terminology Criteria for Adverse Events.

\section{Supplementary Material}

Supplementary figures and tables. http://www.jcancer.org/v09p2640s1.pdf

\section{Competing Interests}

The authors have declared that no competing interest exists.

\section{References}

[1] Siegel RL, Miller KD, Jemal A. Cancer Statistics, 2017. CA Cancer J Clin. 2017; 67: 7- 30.

[2] Venook AP, Papandreou C, Furuse J, et al. The incidence and epidemiology of hepatocellular carcinoma: a global and regional perspective. Oncologist. 2010; 15 (Suppl 4): S5- S13.

[3] Chang L, Wang Y, Zhang J, et al. The best strategy for HCC patients at each BCLC stage: a network meta-analysis of observational studies. Oncotarget. 2017; 8: 20418- 20427.

[4] Li K, Wang HT, He YK, et al. New idea for treatment strategies for Barcelona Clinic Liver Cancer stages based on a network meta-analysis. Medicine. 2017; 96: e6950.

[5] Cammà C, Schepis F, Orlando A, et al. Transarterial chemoembolization for unresectable hepatocellular carcinoma: meta-analysis of randomized controlled trials. Radiology. 2002; 224: 47- 54

[6] Llovet JM, Bruix J. Systematic review of randomized trials for unresectable hepatocellular carcinoma: chemoembolization improves survival. Hepatology. 2003; 37: 429- 442.

[7] Bruix J, Sherman M. Management of hepatocellular carcinoma: an update. Hepatology. 2011; 53: 1020- 1022.

[8] European Association For The Study Of The Liver, European Organisation For Research And Treatment Of Cancer. EASL-EORTC clinical practice guidelines: management of hepatocellular carcinoma. J Hepatol. 2012; 56: 908- 43.

[9] Marelli L, Stigliano R, Triantos C, et al. Transarterial therapy for hepatocellular carcinoma: which technique is more effective? A systematic review of cohort and randomized studies. Cardiovasc Intervent Radiol. 2007; 30: 6- 25.

[10] Varela M, Real MI, Burrel M, et al. Chemoembolization of hepatocellular carcinoma with drug eluting beads: efficacy and doxorubicin pharmacokinetics. J Hepatol. 2007; 46: 474- 81.

[11] Huang K, Zhou Q, Wang R, et al. Doxorubicin-eluting beads versus conventional transarterial chemoembolization for the treatment of hepatocellular carcinoma. J Gastroenterol Hepatol. 2014; 29: 920- 5.

[12] Zou JH, Zhang L, Ren ZG, et al. Efficacy and safety of cTACE versus DEB-TACE in patients with hepatocellular carcinoma: a meta-analysis. J Dig Dis. 2016; 17: 510- 517

[13] Facciorusso A, Licinio R, Muscatiello N, et al. Transarterial chemoembolization: Evidences from the literature and applications in hepatocellular carcinoma patients. World J Hepatol. 2015; 7: 2009- 19.

[14] Moher D, Liberati A, Tetzlaff J, et al. Preferred reporting items for systematic reviews and meta-analyses: the PRISMA statement. Int J Surg. 2010; 8: 336- 41.

[15] Atkins D, Best D, Briss PA, et al. Grading quality of evidence and strength of recommendations. BMJ. 2004; 328: 1490.

[16] Salanti G, Higgins JP, Ades AE, et al. Evaluation of networks of randomized trials. Stat Methods Med Res. 2008; 17: 279- 301. 
[17] Jansen JP, Crawford B, Bergman G, et al. Bayesian meta-analysis of multiple treatment comparisons: an introduction to mixed treatment comparisons. Value Health. 2008; 11: 956- 64

[18] Higgins JP, Thompson SG, Deeks JJ, et al. Measuring inconsistency in meta-analyses. BMJ. 2003; 327: 557- 60.

[19] Brown KT, Do RK, Gonen M, et al. Randomized Trial of Hepatic Artery Embolization for Hepatocellular Carcinoma Using Doxorubicin-Eluting Microspheres Compared With Embolization With Microspheres Alone. J Clin Oncol. 2016; 34: 2046- 53.

[20] Chang JM, Tzeng WS, Pan HB, et al. Transcatheter arterial embolization with or without cisplatin treatment of hepatocellular carcinoma. A randomized controlled study. Cancer. 1994; 74: 2449- 53.

[21] Golfieri R, Giampalma E, Renzulli M, et al. Randomised controlled trial of doxorubicin-eluting beads vs conventional chemoembolisation for hepatocellular carcinoma. Br J Cancer. 2014; 111: 255- 64.

[22] Ikeda M, Kudo M, Aikata H, et al. Transarterial chemoembolization with miriplatin vs. epirubicin for unresectable hepatocellular carcinoma: a phase III randomized trial. J Gastroenterol. 2018; 53: 281- 290.

[23] Kawai S, Okamura J, Ogawa M, et al. Prospective and randomized clinical trial for the treatment of hepatocellular carcinoma--a comparison of lipiodol-transcatheter arterial embolization with and without adriamycin (first cooperative study). The Cooperative Study Group for Liver Cancer Treatment of Japan. Cancer Chemother Pharmacol. 1992; 31 (Suppl): S1- S6.

[24] Kubota K, Hidaka H, Nakazawa T, et al. Prospective, randomized, controlled study of the efficacy of transcatheter arterial chemoembolization with miriplatin for hepatocellular carcinoma. Hepatol Res. 2018; 48: E98- E106.

[25] Liu B, Huang JW, Li Y, et al. Single-Agent versus Combination Doxorubicin-Based Transarterial Chemoembolization in the Treatment of Hepatocellular Carcinoma: A Single-Blind, Randomized, Phase II Trial. Oncology. 2015; 89: 23- 30.

[26] Llovet JM, Real MI, Montaña X et al Arterial embolisation or chemoembolisation versus symptomatic treatment in patients with unresectable hepatocellular carcinoma: a randomised controlled trial. Lancet. 2002; 359: 1734- 9 .

[27] Malagari K, Pomoni M, Kelekis A, et al. Prospective randomized comparison of chemoembolization with doxorubicin-eluting beads and bland embolization with BeadBlock for hepatocellular carcinoma. Cardiovasc Intervent Radiol. 2010; 33: 541- 51.

[28] Meyer T, Kirkwood A, Roughton M, et al. A randomised phase II/III trial of 3-weekly cisplatin-based sequential transarterial chemoembolisation vs embolisation alone for hepatocellular carcinoma. Br J Cancer. 2013; 108: 12529.

[29] Otsuji K, Takai K, Nishigaki Y, et al. Efficacy and safety of cisplatin versus miriplatin in transcatheter arterial chemoembolization and transarterial infusion chemotherapy for hepatocellular carcinoma: A randomized controlled trial. Hepatol Res. 2015; 45: 514- 22.

[30] Sahara S, Kawai N, Sato M, et al. Prospective comparison of transcatheter arterial chemoembolization with Lipiodol-epirubicin and Lipiodol-cisplatin for treatment of recurrent hepatocellular carcinoma. Jpn J Radiol. 2010; 28: 3628.

[31] Sahara S, Kawai N, Sato M, et al. Prospective evaluation of transcatheter arterial chemoembolization (TACE) with multiple anti-cancer drugs (epirubicin, cisplatin, mitomycin c, 5-fluorouracil) compared with TACE with epirubicin for treatment of hepatocellular carcinoma. Cardiovasc Intervent Radiol. 2012; 35: 1363- 71

[32] Shi M, Lu LG, Fang WQ, et al. Roles played by chemolipiodolization and embolization in chemoembolization for hepatocellular carcinoma: single-blind, randomized trial. J Natl Cancer Inst. 2013; 105: 59- 68

[33] Somma F, D'Angelo R, Serra N, Gatta G, Grassi R, Fiore F. Use of Ethanol in the Trans-Arterial Lipiodol Embolization (TAELE) of Intermediated-Stage HCC: Is This Safer than Conventional Trans-Arterial Chemo-Embolization (c-TACE)?. PLoS One. 2015; 10: e0129573.

[34] Wang N, Lv YZ, Xu AH, et al. Application of lobaplatin in trans-catheter arterial chemoembolization for primary hepatic carcinoma. Asian Pac J Cancer Prev. 2014; 15: 647- 50.

[35] Zhao C, Fan L, Qi F, et al. Raltitrexed plus oxaliplatin-based transarterial chemoembolization in patients with unresectable hepatocellular carcinoma. Anticancer Drugs. 2016; 27: 689- 94

[36] Bruix J, Sherman M, Llovet JM, et al. Clinical management of hepatocellular carcinoma. Conclusions of the Barcelona-2000 EASL conference. European Association for the Study of the Liver. J Hepatol. 2001; 35: 421- 30.

[37] Therasse P, Arbuck SG, Eisenhauer EA, et al. New guidelines to evaluate the response to treatment in solid tumors. European Organization for Research and Treatment of Cancer, National Cancer Institute of the United States, National Cancer Institute of Canada. J Natl Cancer Inst. 2000; 92: 205- 16.

[38] Gillmore R, Stuart S, Kirkwood A, et al. EASL and mRECIST responses are independent prognostic factors for survival in hepatocellular cancer patients treated with transarterial embolization. J Hepatol. 2011; 55: 1309- 16.

[39] Lencioni R, Llovet JM. Modified RECIST (mRECIST) assessment for hepatocellular carcinoma. Semin Liver Dis. 2010; 30: 52- 60.

[40] Dueck AC, Mendoza TR, Mitchell SA, et al. Validity and Reliability of the US National Cancer Institute's Patient-Reported Outcomes Version of the Common Terminology Criteria for Adverse Events (PRO-CTCAE). JAMA Oncol. 2015; 1: 1051- 9 .
[41] Raoul JL, Sangro B, Forner A, et al. Evolving strategies for the management of intermediate-stage hepatocellular carcinoma: available evidence and expert opinion on the use of transarterial chemoembolization. Cancer Treat Rev. 2011; 37: 212- 20.

[42] Kirchhoff TD, Bleck JS, Dettmer A, et al. Transarterial chemoembolization using degradable starch microspheres and iodized oil in the treatment of advanced hepatocellular carcinoma: evaluation of tumor response, toxicity, and survival. Hepatobiliary Pancreat Dis Int. 2007; 6: 259- 66.

[43] Minotti G, Menna P, Salvatorelli E, et al. Anthracyclines: molecular advances and pharmacologic developments in antitumor activity and cardiotoxicity. Pharmacol Rev. 2004; 56: 185- 229.

[44] Miyayama S, Yamashiro M, Shibata Y, et al. Comparison of local control effects of superselective transcatheter arterial chemoembolization using epirubicin plus mitomycin C and miriplatin for hepatocellular carcinoma. Jpn J Radiol. 2012; 30: 263- 70

[45] Graziadei IW, Vogel W. Treatment of patients infected with chronic hepatitis genotype 2 and 3: more data, more questions?. Hepatology. 2009; 49: 345- 7 .

[46] Graziadei I, Kelly T, Schirmer M, et al. Antitumor effect of the nucleoside analogs 2-chlorodeoxyadenosine and 2',2'-difluorodeoxycytidine on human hepatoma HepG2 cells. J Hepatol. 1998; 28: 504- 9.

[47] Alberts SR, Reid JM, Morlan BW, et al. Gemcitabine and docetaxel for hepatocellular carcinoma: a phase II North Central Cancer Treatment Group clinical trial. Am J Clin Oncol. 2012; 35: 418- 23.

[48] Zangos S, Eichler K, Balzer JO, et al. Large-sized hepatocellular carcinoma (HCC): a neoadjuvant treatment protocol with repetitive transarterial chemoembolization (TACE) before percutaneous MR-guided laser-induced thermotherapy (LITT). Eur Radiol. 2007; 17: 553- 63.

[49] Vogl TJ, Naguib NN, Nour-Eldin NE, et al. Retrospective study on the use of different protocols for repeated transarterial chemoembolization in the treatment of patients with hepatocellular carcinoma. Acad Radiol. 2012; 19: 434- 9.

[50] Yang TS, Lin YC, Chen JS, et al. Phase II study of gemcitabine in patients with advanced hepatocellular carcinoma. Cancer. 2000; 89: 750- 6 .

[51] Hammond JS, Franko J, Holloway SE, et al. Gemcitabine transcatheter arterial chemoembolization for unresectable hepatocellular carcinoma. Hepatogastroenterology. 2014; 61: 1339- 43.

[52] Xie F, Zang J, Guo X, et al. Comparison of transcatheter arterial chemoembolization and microsphere embolization for treatment of unresectable hepatocellular carcinoma: a meta-analysis. J Cancer Res Clin Oncol. 2012; 138: 455- 62.

[53] Park JH, Han JK, Chung JW, et al. Superselective transcatheter arterial embolization with ethanol and iodized oil for hepatocellular carcinoma. J Vasc Interv Radiol. 1993; 4: 333-9.

[54] Cheng Y, Kan Z, Chen C, et al. Efficacy and safety of preoperative lobar or segmental ablation via transarterial administration of ethiodol and ethanol mixture for treatment of hepatocellular carcinoma: clinical study. World J Surg. 2000; 24: 844-

[55] Facciorusso A, Licinio R, Muscatiello N, et al. Transarterial chemoembolization: Evidences from the literature and applications in hepatocellular carcinoma patients. World J Hepatol. 2015; 7: 2009- 19.

[56] Tsochatzis EA, Fatourou E, O'Beirne J, et al. Transarterial chemoembolization and bland embolization for hepatocellular carcinoma. World J Gastroenterol. 2014; 20: 3069- 77 .

[57] Imai N, Ishigami M, Ishizu $Y$, et al. Transarterial chemoembolization for hepatocellular carcinoma: A review of techniques. World J Hepatol. 2014; 6: 844- 50. 